Article

\title{
Sustainability Assessment of a Single-Use Plastics Ban
}

\author{
Timo Herberz ${ }^{1, *} \mathbb{D}$, Claire Y. Barlow ${ }^{1}$ and Matthias Finkbeiner ${ }^{2}$ \\ 1 Department of Engineering, University of Cambridge, Trumpington Street, Cambridge CB2 1PZ, UK; \\ cyb1@cam.ac.uk \\ 2 Chair of Sustainable Engineering, Technische Universität Berlin, Straße des 17. Juni 135, 10623 Berlin, \\ Germany; matthias.finkbeiner@tu-berlin.de \\ * Correspondence: th560@alumni.cam.ac.uk
}

Received: 5 April 2020; Accepted: 30 April 2020; Published: 5 May 2020

check for updates

\begin{abstract}
Governments around the world are introducing single-use plastics bans to alleviate plastic marine pollution. This paper investigates whether banning single-use plastic items is an appropriate strategy to protect the environment. Product life cycle assessment was conducted for single-use plastic and single-use non-plastic alternatives. The life cycle impacts of the two product categories were compared and scaled according to EU consumption of 2016. The results show that a single-use plastics ban would decrease plastic marine pollution in the EU by $5.5 \%$ which equates to a $0.06 \%$ decrease globally. However, such a ban would increase emissions contributing to marine aquatic toxicity in the EU by $1.4 \%$. This paper concludes that single-use items are harmful to the environment regardless of their material. Therefore, banning or imposing a premium price on single-use items in general and not only single-use plastic items is a more effective method of reducing consumption and thereby pollution. The plastics ban only leads to a small reduction of global plastic marine pollution and thus provides only a partial solution to the problem it intends to solve.
\end{abstract}

Keywords: single-use plastics; plastics ban; plastic marine pollution; LCA; plastics policy

\section{Introduction}

It is impossible to imagine today's world without plastic. Due to its versatility, affordability and durability, plastic is found in an almost infinite number of applications including clothing, machinery, construction, electronics, transportation, agriculture and packaging, with the last contributing the most to the demand for plastic [1]. Globally, over 300 million tonnes of plastic are produced each year and the trend is increasing [1]. Approximately 275 million tonnes of global plastic waste were generated in 2010 [2], and this figure has increased since then [3]. While being a positive characteristic during use, the longevity of plastic causes problems at the waste disposal stage: in 2015, the amount of plastic which had accumulated in landfills or the natural environment was estimated to be approximately 5000 million tonnes and it is predicted to increase to 12,000 million tonnes by mid-century [3].

The accumulation of plastic in the natural environment also occurs in the oceans. It is estimated that 4.8 to 12.7 million tonnes of plastic entered the oceans in 2010 alone [2]. Plastic fragments can be found in marine environments worldwide [4]. Plastic in the oceans does not only cause concerns for the environment and human health [5], but can also have negative impacts on local economies [6]. These concerns are shared among supranational organisations, including the UN and the EU, national governments, non-governmental organisations, scientists, and members of the public $[7,8]$, who all identify marine plastic as a global problem.

Policy is a lever to address the problem of plastic marine pollution. Many policies have been enacted worldwide aiming to prevent the discharge of plastic into the oceans [6,9]. However, in the 
past, many regulations have been shown to be ineffective at preventing the discharge of plastic into the oceans $[7,10]$. Furthermore, legislation influencing the consumption of plastic products can lead to unintended consequences such as a shift in consumption from plastic to another material [11]. Therefore, finding effective solutions requires a holistic life cycle approach $[7,12]$.

In 2021, the EU will introduce a market restriction on several single-use plastic items, such as cotton bud sticks, cutlery, plates, straws, drink stirrers and sticks for balloons [13]. The market restriction is part of the single-use plastics directive which focuses on the 27,000 tonnes of plastic from fishing gear and single-use plastics which enter the marine environment every year in the EU [14]. Apart from the market restriction, the directive foresees new product design requirements, extended producer responsibility and awareness raising measures [13]. The estimated reduction in greenhouse gas (GHG) emissions associated with the introduction of the directive is 2.63 million tonnes per year [14]. The directive states that its "main objective [ ... ] is to prevent and to reduce the impact of certain plastic products on the environment, in particular the aquatic environment" [13].

The evidence base used for the market restriction is flawed in four ways. First, the life cycle assessment (LCA) does not show ISO conformity [15]. Second, it does not include the End-of-Life (EoL) stage [15], which gives an advantage to biodegradable products in the assessment. Specifically, it ignores the methane emissions of biodegradable products when landfilled which is where a third of EU waste ends up [16]. Third, the LCA performed by the European Commission (EC) only considers air pollutants [15]. Again, this favours products which are based on agricultural and forestry produce and disregards that these often lead to significant effluents to water bodies. Fourth, the results of the environmental assessment are not communicated transparently. For example, it is stated that "there might be a minor increase in land use due to a switch to paper and wood" [14]. However, this increase in land use is not further discussed nor quantified.

Not only is the environmental assessment flawed but also the impact assessment makes unsupported assumptions. The EC [17] assumes that the directive will cause a switch in consumption from single-use items to multiple-use items of $10 \%$ to $90 \%$ depending on the product. It is furthermore assumed that overall demand will decrease by $50 \%$ for some single-use items due to the directive [17]. However, these assumptions are not justified with evidence. It seems more likely that almost the same number of single-use items will be consumed which would then be made from different materials such as paper and wood [11].

There is a lack of studies which assess how plastic compares to other materials available for single-use items. Wood has been the subject of comparative LCAs but only in the construction sector [18-20]. LCAs which compare paper products with polymer products only exist for carrier bags. Lewis et al. [21] reviewed a number of comparative LCA studies and found that "paper has the highest environmental impact in most categories". In contrast, Mattila et al. [22] state in their LCA study which took different EoL scenarios into account that they "could not discern plastic, paper, and cotton bags without limiting the analysis to some subset of situations". A UK Environment Agency study points to the importance of reusing carrier bags and finds that paper bags need to be reused three times to reduce the global warming potential below that of single-use, high-density polyethylene carrier bags [23].

LCA has been criticised for not considering mismanaged waste and therefore not taking impacts from plastic marine pollution into account. Boucher and Billard [24] argue that current LCAs neglect plastic pollution. Schweitzer et al. [25] as well as Lewis et al. [21] are critical of the fact that LCAs do not consider environmental leakage in their waste management scenarios. In 2016, a review of quantitative approaches for cause-effect assessments included marine plastic debris but stated that, at the time, there were no effect factors which quantify the effect of marine plastic on biodiversity [26]. Only recent research has started developing an effect factor approach for entanglement with marine plastic [27] and assessed the risk of marine littering of plastic bags [28]. In the present research, we want to build on this research and explicitly include plastic marine pollution in the life cycle impact assessment. 
The objective of this study is to assess the effect on the environment of a single-use plastic market restriction on certain consumer items which was proposed in 2018 by the EC [13]. To achieve this objective, product LCA was conducted for single-use plastic items and single-use non-plastic alternatives. The life cycle impacts of the two product types were compared and scaled according to EU consumption. LCA was identified as the appropriate method for this research as it allows the quantification of environmental impacts of different product systems with the same function. The main research question to be answered is whether the EU single-use plastics ban is appropriate to improve the quality of the marine environment and whether other solutions to the problem of plastic marine pollution exist.

While this paper offers novel insights, it also has limitations. The novelties of this study concern not only the methodology but also the case study outcome. From a methodological point of view, the novelty of this study is the assessment of plastic marine pollution as an impact category. The chosen probabilistic approach is straight forward and therefore easy to replicate by other researchers. The case study deals with the policy assessment of a single-use plastics ban. While comparative LCAs exist for individual product comparisons, there is no literature-based evidence of an environmental policy assessment of a plastics ban which causes a large-scale shift from one product to another. One limitation of this study is that it takes a static approach to consumption and emission levels and considers only one year as a reference period. Another limitation is that the study does not perform an endpoint damage analysis and therefore does not come to a clear conclusion.

\section{Materials and Methods}

This study is structured by goal and scope definition, inventory analysis, impact assessment and life cycle interpretation according to ISO 14040 [29] and 14044 [30].

\subsection{Goal and Scope Definition}

This study is an assessment of an EU policy proposal. The intended application is to inform decision makers in government, especially in public policy related to plastics. This study also addresses the scientific community working on LCA as well as plastics. The results of this LCA study are intended to be used in comparative assertions to be disclosed to the public. The following sub-section defines the product systems and their functions (Table 1).

\subsubsection{Product Systems and Their Functions}

Definition of product systems, specifications, functions and functional units (Table 1).

Table 1. Definition of product systems, specifications, functions and functional units.

\begin{tabular}{llll}
\hline Product system & Specification & Function & Functional unit \\
\hline $\begin{array}{l}\text { Single-use cotton } \\
\text { bud stick }\end{array}$ & Exclusion of cotton & Attachment for cotton buds & $\begin{array}{l}\text { Provision of } 1000 \text { cotton bud sticks } \\
\text { (without cotton) }\end{array}$ \\
\hline $\begin{array}{l}\text { Single-use cutlery } \\
\text { (knife) }\end{array}$ & Length: $16.5-18 \mathrm{~cm}$ & Provision of a knife for use & Provision of $1000 \mathrm{knives} \mathrm{for} \mathrm{use}$ \\
\hline $\begin{array}{l}\text { Single-use cutlery } \\
\text { fork) }\end{array}$ & Length: $14-18 \mathrm{~cm}$ & Provision of a fork for use & Provision of 1000 forks for use \\
\hline $\begin{array}{l}\text { Single-use cutlery } \\
(\text { spoon) }\end{array}$ & Length: $14.5-16.5 \mathrm{~cm}$ & Provision of a spoon for use & Provision of 1000 spoons for use \\
\hline $\begin{array}{l}\text { Single-use cutlery } \\
\text { (teaspoon) }\end{array}$ & Length: $11-12.5 \mathrm{~cm}$ & Provision of a teaspoon for use & Provision of 1000 teaspoons for use \\
\hline $\begin{array}{l}\text { Single-use straw } \\
\text { Single-use stirrer }\end{array}$ & Length: $19-21 \mathrm{~cm}$ & Provision of a straw for use & Provision of 1000 straws for use \\
\hline \begin{tabular}{l} 
Single-use plate \\
\hline
\end{tabular} & Diameter: $22-24 \mathrm{~cm}$ & Provision of a plate for use & Provision of 1000 plates for use \\
\hline
\end{tabular}




\subsubsection{System Boundaries and Allocation}

All unit processes from cradle to grave were included in the system boundary (Figure 1). The required infrastructure and equipment to execute these unit processes were not included in the analysis. Where cut-off criteria were applied, this is indicated in Section 2.1.4. Cut-off criteria were also applied to the life cycle inventory (LCI) datasets used for this study which can be found in the GaBi ts 8.7 documentation of the respective LCI datasets. The deployed LCI datasets consider transportation processes during the raw material production. Furthermore, this study considered the transportation from material production to manufacturing, from manufacturing to the retailer and from consumer to landfill, incineration, the recycling or composting facility. The transportation between the retailer and consumer lay outside of the system boundary of this study.

No specific allocation rules were applied by this study, although they were applied to the LCI datasets used for this study which can be found in the GaBi ts 8.7 documentation of the respective LCI datasets. No environmental burdens were allocated to by-products of negligible economic value. Full credits were given for steam and electricity recovered from landfill gas collection and incineration. Partial credit was given for recycled material (PP, paper, PS) after consideration of the energy requirements for recycling. A correction factor of 0.6 was applied to account for the loss of value compared to virgin material, which is discussed in Section 4.1.2.

\subsubsection{Impact Categories, Category Indicator Results and Methodology of Impact Assessment}

Six impact categories were assessed by this study: global warming potential, acidification potential, eutrophication potential, marine aquatic toxicity, abiotic depletion and plastic marine pollution. The respective category indicator results are expressed in $\mathrm{kg} \mathrm{CO}_{2}$ equivalents $\left(\mathrm{CO}_{2} \mathrm{e}\right), \mathrm{kg} \mathrm{SO}_{2}$ equivalents, $\mathrm{kg}$ phosphate equivalents, $\mathrm{kg}$ dichlorobenzene (DCB) equivalents, megajoules and $\mathrm{kg}$ marine plastic. The chosen methodology of impact assessment for the first five impact categories is CML 2001 [31,32]. The sixth impact category is a newly proposed impact category which is an inventory parameter, similar to abiotic depletion, based on Jambeck et al. [2], without classification or characterisation.

An impact category for plastic marine pollution is so far lacking in the field of life cycle assessment. However, plastic marine pollution has become a concerning environmental issue on a global scale. Therefore, the demand from governments and businesses for assessments which also consider plastic marine pollution will increase. Plastic marine pollution can be assessed in different ways of which the most apparent are by count or by weight. In this study, we propose to assess plastic marine pollution by weight as a midpoint category on which different effect factor models (e.g., for entanglement and ingestion) can then build to research the damage created by plastic marine pollution. The weight fraction of a plastic product that ultimately contributes to plastic marine pollution can be ascertained through statistical analysis of the fate of plastic products. Thereby, a robust approach to assess plastic marine pollution is created on which future research can build.

\subsubsection{Data and Assumptions}

All data used in this study are from post 2000 and represent European standards and technologies. There is coverage of at least $95 \%$ of mass and energy of the input and output flows for all processes where LCI data were used. Sources of data were commercial LCI databases, public LCI databases, measured data, data from peer-reviewed literature, data from reports of public bodies and data from machine manufacturers.

Products from conventional plastics and from renewable resources for all product categories mentioned in Section 2.1.1. (see Figures S15-S22) were weighed with a precision scale (Table S1) and infrared (IR) spectroscopy was deployed to identify unknown polymers (Figures S1-S14). Where more than one product from one material was identified, the mean of both weights was calculated. Unidentifiable polymers were excluded from the analysis. 

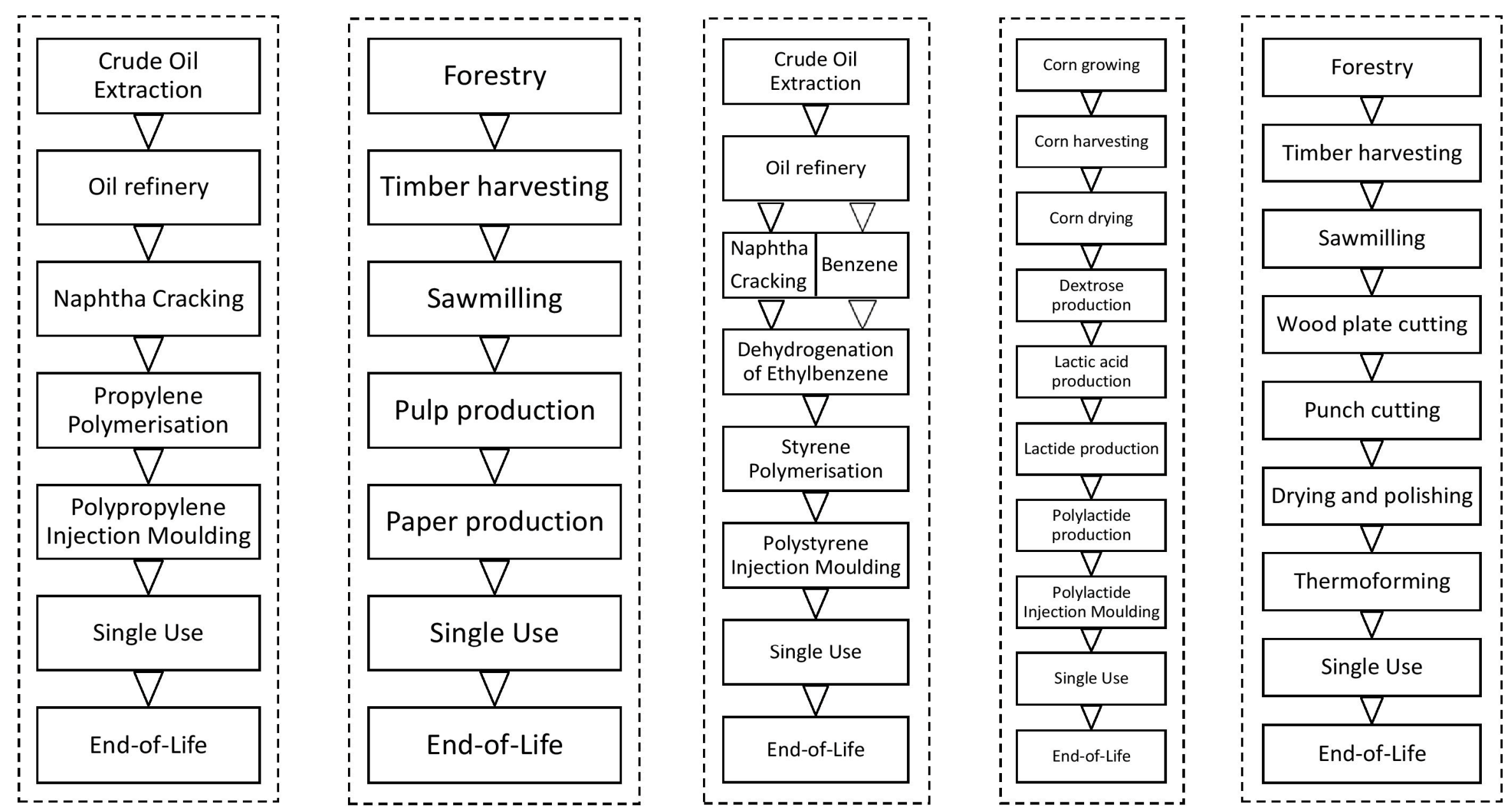

Figure 1. Polypropylene (PP), paper, polystyrene (PS), polylactide (PLA) and wood process flow diagrams (from left to right) and system boundaries (dotted line). Inputs to the systems: electricity, fuel, chemicals, water. Outputs of the systems: emissions to air, water and soil, by-products. 
Data for material sourcing derived primarily from LCI datasets. The paper LCI dataset stemmed from the European Life Cycle database and represents the EU-25 technology and production mix (see also Table S2). The dataset for PLA was provided by NatureWorks ${ }^{\mathrm{TM}}$, the leading supplier of PLA [33]. The PP and PS datasets represent the German technology mix and were provided by GaBi ts 8.7. Wooden single-use items are normally made from beech or birch. Here, a beech timber dataset provided by GaBi ts 8.7 was deployed which represents the EU-28 technology and production mix.

Different materials require varied manufacturing processes. In the case of paper, no specific manufacturing data were found. Therefore, it was assumed that the environmental impacts of paper cotton bud sticks, paper plates and paper straws are identical to the impacts of graphic paper per unit of weight. PLA, PP and PS undergo the same manufacturing step of injection moulding provided by GaBi ts 8.7 (see also Table S2). The electricity and water datasets both represent the EU-28 technology and production mix and were provided by GaBi ts 8.7. Manufacturers of machines to produce wooden items were the source of corresponding product manufacturing data (see Table S2) [34-36].

This study assumed that waste from all single-use items either ends up in landfill or incineration. In the EU, $32 \%$ of municipal waste goes to landfill, $42 \%$ is recycled, composted or digested, $20 \%$ is incinerated with energy recovery and $2 \%$ is incinerated without energy recovery [16]. Therefore, the ratio between landfill and incineration is roughly $60 / 40$ which is the EoL scenario chosen in this study. Of the $2.5 \%$ of mismanaged plastic waste in the $\mathrm{EU}, 15 \%$ to $40 \%$ convert into marine debris [2]. In this study it was assumed that $25 \%$ of mismanaged waste ends up in the ocean and that only PP and PS contribute to plastic marine pollution.

EoL process data were primarily taken from GaBi ts 8.7. Paper landfilling and incineration data represent the EU-28 technology and production mix provided by GaBi ts 8.7. PLA landfilling and incineration data were taken from Papong et al. [37] and GaBi ts 8.7 (EU-28 production mix) respectively. PP, PS and wood landfilling and incineration data represent the EU-28 production mix provided by $\mathrm{GaBi}$ ts 8.7. According to the 20/2 ratio of incinerators with and without energy recovery, it was inferred that $90.9 \%$ of incinerators recover energy. The electricity credit from landfilling and incineration was based on the electricity dataset mentioned earlier in this chapter. The steam credit from incineration was based on the EU-28 technology and production mix for process steam from natural gas with $85 \%$ process efficiency provided by GaBi ts 8.7 .

Transportation distances were based on assumptions and were not measured. Based on van der Harst et al. [38], the transportation distances were assumed to be $500 \mathrm{~km}$ from material production to manufacturing, $600 \mathrm{~km}$ from manufacturing to retailer and $100 \mathrm{~km}$ from consumer to landfill and incineration (see also Table S2).

\subsection{Inventory Analysis}

The inventory analysis involved "the compilation and quantification of inputs and outputs for a product throughout its life cycle" [29]. Inputs to the product systems include materials and energy, while outputs include emissions to air, water and soil. The process data were compiled for every product by using the software tool GaBi ts 8.7 and the inventory analysis was performed based on the functional units described in Section 2.1.1.

\subsection{Impact Assessment}

The impact assessment involved "associating inventory data with specific environmental impact categories and category indicators, thereby attempting to understand these impacts" [29]. Besides the newly proposed impact category plastic marine pollution, the impact categories and category indicators described in Section 2.1.3 were implemented in line with the methodology of impact assessment CML $2001[31,32]$ in the software tool GaBi ts 8.7. 


\subsection{Sensitivity Analysis 1}

According to ISO [30], a sensitivity analysis was conducted. In this study, three aspects were identified which require further analysis: the product weights, transportation and the EoL phase. This sensitivity analysis explored how the variation of product weights by $\pm 50 \%$ influences the LCIA results. It further explored by how much the LCIA results change when the transportation distances are varied by $\pm 10 \%$. Finally, the effect of an alternative EoL scenario which is different from that described in Section 2.1.4 was explored.

In the alternative EoL scenario, waste from single-use items ends up in landfill, incineration, recycling or composting. In the case of paper, a recycling rate of $72.3 \%$ was assumed based on European Paper Recycling Council [39]. For PLA and wood, a composting rate of $25 \%$ was assumed based on European Compost Network [40]. For PP and PS, a recycling rate of 31.1\% was assumed based on PlasticsEurope [1]. The remaining waste streams were split between landfill and incineration in the same way as in the base scenario. The transportation distances from the consumer to recycling and composting facilities were assumed to be $300 \mathrm{~km}$ based on van der Harst et al. [38].

The data for recycling processes were retrieved from GaBi ts 8.7 and peer-reviewed literature. Data from Arena et al. [41] were used for the paper recycling process (see also Table S2). Windrow composting process data including credits were provided by the University of Natural Resources and Life Sciences Vienna and GaBi ts 8.7. Plastic recycling process data represents the EU-28 production mix and was provided by GaBi ts 8.7 (see also Table S2).

\subsection{Assessment of the Single-Use Plastics Ban}

The assessment of the single-use plastics ban which the EU plans to introduce from 2021 was achieved by combining the LCIA results with annual consumption figures which were then normalised regionally. The 2016 consumption data was taken from EC [17] and is based on two market reports [42,43]. Consumption figures for plastic cotton bud sticks, cutlery, straws and stirrers are 48.9 billion, 84.5 billion, 207 billion and 216 billion, respectively. Since no data was available for plastic plates, it was assumed that the number of plates is half the number for cutlery. It was further assumed that the four types of cutlery assessed by this study are consumed in equal amounts. For simplification of the assessment, static consumption levels and a one-for-one replacement of single-use plastic items by single-use non-plastic items is assumed.

In the analysis of the plastics ban, the category indicator results of items from conventional plastics $\left(\mathrm{CI}_{\text {conventional }}\right)$ were subtracted from the category indicator results of the items from renewable resources $\left(\mathrm{CI}_{\text {renewable }}\right)$. Where two items of different materials existed, the means of the category indicator results were taken. PLA was excluded from the analysis since it falls under the plastics ban and is still a niche material in comparison to PP and PS cutlery. The results of the subtractions mentioned before were then multiplied by the respective annual consumption figures $(C F)$ and summed up (Equation (1)).

$$
C I_{\text {ban }}=\sum_{k=1}^{8}\left(\mathrm{CI}_{\text {renewable }, k}-\mathrm{CI}_{\text {conventional }, k}\right) * C F_{k}
$$

Finally, the six category indicator results of the plastics ban were divided by regional EU-28 annual emission data from GaBi ts 8.7 and Jambeck et al. [2]. This was done to assess the change in emissions which the plastics ban causes in relation to overall emissions.

\subsection{Sensitivity Analysis 2}

To complement the sensitivity analysis carried out in Section 2.4, one more aspect of the analysis in this study was explored through the means of a sensitivity analysis. This sensitivity analysis explored the impact on the assessment of the single-use plastics ban when a reduction of the consumption of single-use items of $10 \%$ and $20 \%$, due to the introduction of the single-use plastics ban, is assumed. 


\section{Results}

For conciseness, the results of the product LCAs and the results of the variation of product weights are presented together in Appendix A. Per definition, paper, wood and PLA do not cause plastic marine pollution. Depending on the product, plastic alternatives show better (cotton bud sticks), similar (straws) or worse (plates) overall results than their paper counterparts. Wood alternatives often show better results than their plastic counterparts and have the lowest emissions with regards to the global warming potential. PLA alternatives show the highest emissions in many cases. The error bars, representing a variation of product weights by $\pm 50 \%$, overlap in many instances. The remaining results of the sensitivity analysis and the overall assessment of the single-use plastics ban are presented in this section.

\subsection{Sensitivity Analysis 1: Transportation}

The results of the sensitivity analysis show by how much the category indicator results change when the transportation distances are varied by $\pm 10 \%$ (Table 2 ). The category indicator results of the abiotic depletion potential change by more than one percent for all paper products and three out of five products made of wood. All other values are below one percent and the values for plastic marine pollution are zero.

Table 2. Changes in case of a variation of the transportation distances by $\pm 10 \%$. Values exceeding $1 \%$ are shown in bold.

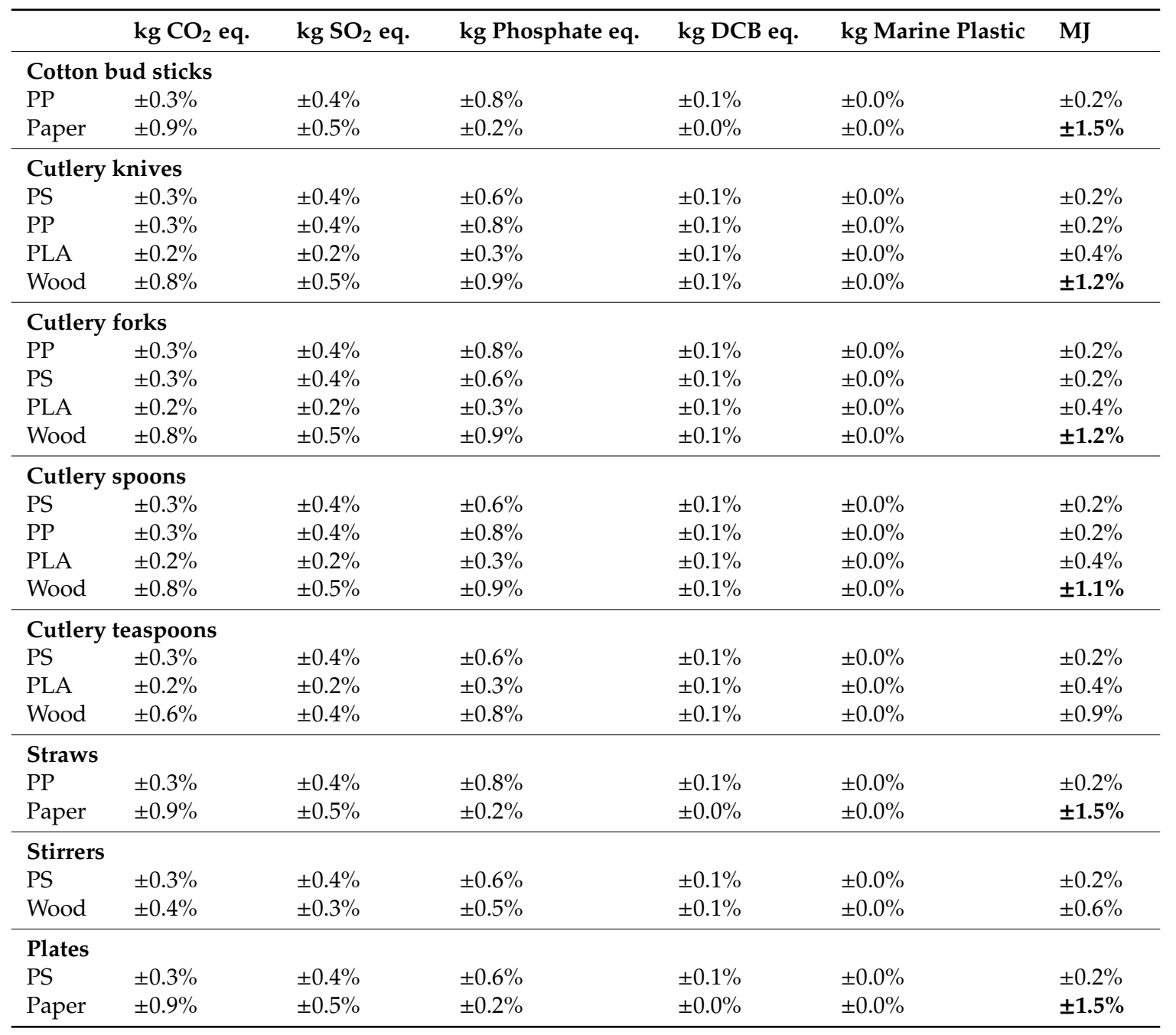




\subsection{Sensitivity Analysis 1: End-Of-Life}

The results of the sensitivity analysis show the changes to the category indicator results presented in Appendix A if a recycling and composting scenario is assumed (Table 3). The scenario change shows significant impact in the case of all paper products on the impact categories global warming potential, acidification potential, eutrophication potential and marine aquatic toxicity. Furthermore, it reduces the global warming contribution of all PLA and PS products and most products made of wood by more than $10 \%$. Finally, for all PS products the abiotic depletion potential is reduced by more than $10 \%$.

Table 3. Changes in case of a recycling and composting scenario. Values falling short of $-10 \%$ are shown in bold.

\begin{tabular}{|c|c|c|c|c|c|c|}
\hline & $\mathrm{kg} \mathrm{CO} 2$ eq. & kg SO${ }_{2}$ eq. & kg Phosphate eq. & kg DCB eq. & kg Marine Plastic & MJ \\
\hline \multicolumn{7}{|c|}{ Cotton bud sticks } \\
\hline PP & $-8.9 \%$ & $0.9 \%$ & $-5.2 \%$ & $2.8 \%$ & $0.0 \%$ & $-9.9 \%$ \\
\hline Paper & $-35.2 \%$ & $-22.7 \%$ & $-37.1 \%$ & $-35.5 \%$ & $0.0 \%$ & $9.9 \%$ \\
\hline \multicolumn{7}{|c|}{ Cutlery knives } \\
\hline PS & $-10.7 \%$ & $-2.1 \%$ & $-7.1 \%$ & $3.9 \%$ & $0.0 \%$ & $-10.7 \%$ \\
\hline PP & $-9.0 \%$ & $1.0 \%$ & $-5.1 \%$ & $2.8 \%$ & $0.0 \%$ & $-9.9 \%$ \\
\hline PLA & $-12.7 \%$ & $2.7 \%$ & $1.2 \%$ & $4.2 \%$ & $0.0 \%$ & $2.8 \%$ \\
\hline Wood & $-15.7 \%$ & $3.3 \%$ & $2.5 \%$ & $4.6 \%$ & $0.0 \%$ & $5.6 \%$ \\
\hline \multicolumn{7}{|c|}{ Cutlery forks } \\
\hline $\mathrm{PP}$ & $-9.0 \%$ & $1.0 \%$ & $-5.1 \%$ & $2.8 \%$ & $0.0 \%$ & $-9.9 \%$ \\
\hline PS & $-10.7 \%$ & $-2.1 \%$ & $-7.1 \%$ & $3.9 \%$ & $0.0 \%$ & $-10.7 \%$ \\
\hline PLA & $-12.7 \%$ & $2.7 \%$ & $1.2 \%$ & $4.2 \%$ & $0.0 \%$ & $2.8 \%$ \\
\hline Wood & $-15.5 \%$ & $3.3 \%$ & $2.4 \%$ & $4.5 \%$ & $0.0 \%$ & $5.6 \%$ \\
\hline \multicolumn{7}{|c|}{ Cutlery spoons } \\
\hline PS & $-10.7 \%$ & $-2.1 \%$ & $-7.1 \%$ & $3.9 \%$ & $0.0 \%$ & $-10.7 \%$ \\
\hline PP & $-9.0 \%$ & $1.0 \%$ & $-5.1 \%$ & $2.8 \%$ & $0.0 \%$ & $-9.9 \%$ \\
\hline PLA & $-12.7 \%$ & $2.7 \%$ & $1.2 \%$ & $4.2 \%$ & $0.0 \%$ & $2.8 \%$ \\
\hline Wood & $-14.6 \%$ & $3.1 \%$ & $2.3 \%$ & $4.3 \%$ & $0.0 \%$ & $5.2 \%$ \\
\hline \multicolumn{7}{|c|}{ Cutlery teaspoons } \\
\hline PS & $-10.7 \%$ & $-2.1 \%$ & $-7.1 \%$ & $3.9 \%$ & $0.0 \%$ & $-10.7 \%$ \\
\hline PLA & $-12.7 \%$ & $2.7 \%$ & $1.2 \%$ & $4.2 \%$ & $0.0 \%$ & $2.8 \%$ \\
\hline Wood & $-11.9 \%$ & $2.5 \%$ & $2.0 \%$ & $3.4 \%$ & $0.0 \%$ & $4.1 \%$ \\
\hline \multicolumn{7}{|c|}{ Straws } \\
\hline $\mathrm{PP}$ & $-9.0 \%$ & $1.0 \%$ & $-5.1 \%$ & $2.8 \%$ & $0.0 \%$ & $-9.9 \%$ \\
\hline Paper & $-35.1 \%$ & $-22.7 \%$ & $-37.1 \%$ & $-35.4 \%$ & $0.0 \%$ & $9.9 \%$ \\
\hline \multicolumn{7}{|c|}{ Stirrers } \\
\hline PS & $-10.7 \%$ & $-2.1 \%$ & $-7.1 \%$ & $3.9 \%$ & $0.0 \%$ & $-10.7 \%$ \\
\hline Wood & $-7.7 \%$ & $1.7 \%$ & $1.5 \%$ & $2.2 \%$ & $0.0 \%$ & $2.6 \%$ \\
\hline \multicolumn{7}{|l|}{ Plates } \\
\hline PS & $-10.7 \%$ & $-2.1 \%$ & $-7.1 \%$ & $3.9 \%$ & $0.0 \%$ & $-10.7 \%$ \\
\hline Paper & $-35.1 \%$ & $-22.7 \%$ & $-37.1 \%$ & $-35.4 \%$ & $0.0 \%$ & $9.9 \%$ \\
\hline
\end{tabular}

\subsection{Results of the Single-Use Plastics Ban Assessment}

The results of the assessment of the single-use plastics ban reveal positive values for acidification, eutrophication and marine aquatic toxicity, while they reveal negative values for global warming, plastic marine pollution and abiotic depletion (Figure 2). The annual emissions contributing to global warming are reduced by approximately 1.56 million tons of $\mathrm{CO}_{2}$ equivalents and the annual plastic marine pollution is reduced by approximately 5 million $\mathrm{kg}$ of plastic. 


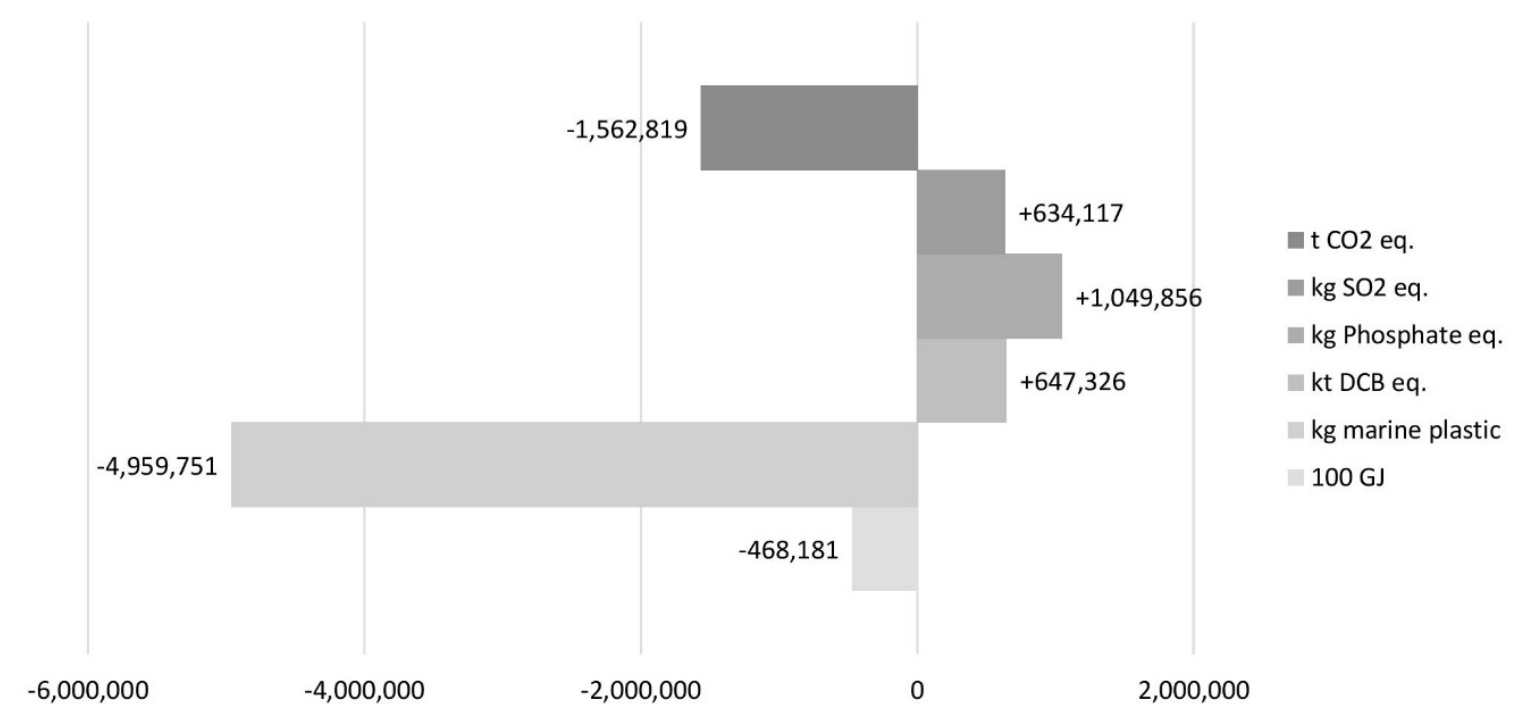

Figure 2. Impacts of a single-use plastics ban in the EU. The chart shows the increase or decrease of annual emissions for the six assessed impact categories. The legend is in the same order as the bars from top to bottom.

After the regional normalisation with EU-28 emission data, the results reveal the contribution to overall annual emission savings and increases in the EU (Figure 3). The ban saves under $1 \%$ of emissions contributing to global warming and abiotic depletion. Furthermore, the ban increases emissions contributing to acidification and eutrophication by less than $1 \%$. Nevertheless, it increases emissions contributing to marine aquatic toxicity by approximately $1.4 \%$ and reduces emissions contributing to plastic marine pollution by approximately $5.5 \%$.

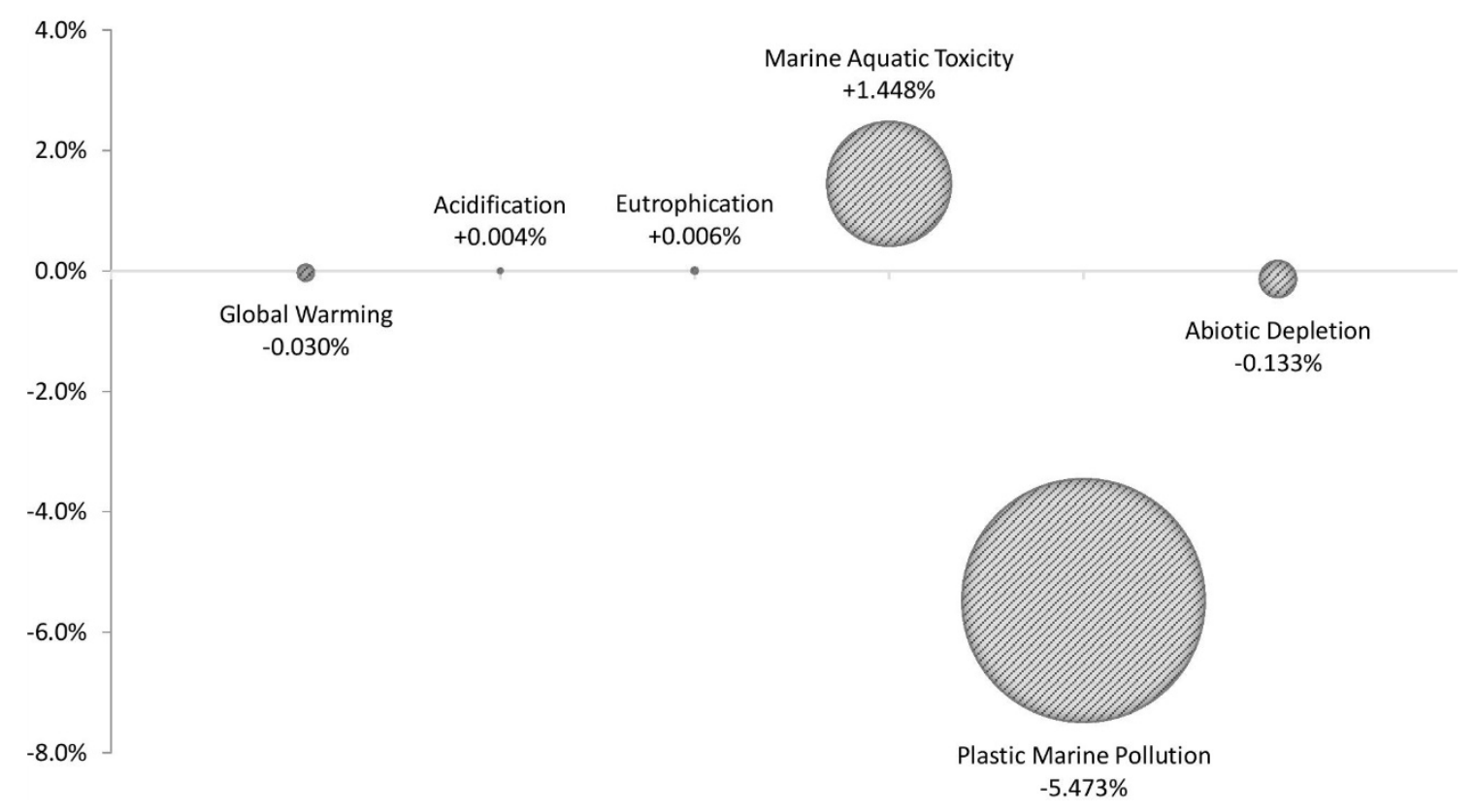

Figure 3. Impacts of a single-use plastics ban in the EU. Percentages show the increase or decrease of annual emissions for the six assessed impact categories in relation to total emissions in the EU.

\subsection{Sensitivity Analysis 2: A Reduction of Consumption}

The results of the sensitivity analysis exploring a reduction of consumption of single-use items due to the introduction of the single-use plastics ban show that the environmental impacts reduce with the consumption figures apart from $\mathrm{kg}$ marine plastic (plastic marine pollution) which remains 
unchanged (Table 4). In the case of $\mathrm{kg} \mathrm{SO}_{2}$ eq. (acidification), the results even become negative with a $20 \%$ reduction.

Table 4. Results of the sensitivity analysis 2 for which a reduction of the consumption of single-use items of $10 \%$ and $20 \%$ is assumed. The absolute values correspond to Figure 2 while the relative values correspond to Figure 3.

\begin{tabular}{|c|c|c|c|c|c|c|}
\hline & t $\mathrm{CO}_{2}$ eq. & $\mathrm{kg} \mathrm{SO}_{2}$ eq. & kg Phosphate eq. & kt DCB eq. & kg Marine Plastic & $100 \mathrm{GJ}$ \\
\hline \multicolumn{7}{|c|}{ Reduction of consumption by $10 \%$} \\
\hline Absolute & $-1,710,047$ & 190,289 & 890,086 & 571,823 & $-4,959,751$ & $-481,576$ \\
\hline Relative & $-0.033 \%$ & $0.001 \%$ & $0.005 \%$ & $1.279 \%$ & $-5.473 \%$ & $-0.137 \%$ \\
\hline \multicolumn{7}{|c|}{ Reduction of consumption by $20 \%$} \\
\hline Absolute & $-1,857,275$ & $-253,538$ & 730,317 & 496,321 & $-4,959,751$ & $-494,970$ \\
\hline Relative & $-0.036 \%$ & $-0.002 \%$ & $0.004 \%$ & $1.110 \%$ & $-5.473 \%$ & $-0.141 \%$ \\
\hline
\end{tabular}

\section{Discussion}

This discussion chapter fulfils two needs. First, it comprises the life cycle interpretation $[29,30]$. Second, it discusses the potential alternatives to and the sustainability of the single-use plastics ban.

\subsection{Life Cycle Interpretation}

The life cycle interpretation phase "should deliver results that are consistent with the defined goal and scope and which reach conclusions, explain limitations and provide recommendations" [29]. ISO [30] specifies that the interpretation "shall include an assessment and a sensitivity check of the significant inputs, outputs and methodological choices in order to understand the uncertainty of the results".

\subsubsection{Product Life Cycle Assessments}

Where paper was compared to either PP or PS (cotton bud sticks, straws, plates), the results show that the GHG savings are dependent on the weights of the respective products. However, emissions contributing to acidification, eutrophication and marine aquatic toxicity are higher for paper almost independent of the weight variation performed in the sensitivity analysis. The only exception is acidification in the case of single-use plates. For abiotic depletion, paper always performs better-the value is weight variation dependent for the paper-PP comparison, but weight variation independent for the paper-PS comparison. These results show that PP generally performs better than PS in comparison to paper. PP shows a similar or better performance than paper apart from the category plastic marine pollution.

Where wood was compared to PP, PS and PLA (cutlery, stirrers), wood shows lower GHG emissions which are independent of the weight variation in three out of five cases. PLA always performs worst in terms of GHG emissions. This can be explained partly by the deployed landfill scenario from Papong et al. [37] described as the "potential methane generation" from PLA. The process steps involved in making PLA items (see Figure 1) lead it to perform the worst in terms of acidification (almost independent of weight variation), eutrophication (independent of weight variation) and marine aquatic toxicity (almost independent of weight variation). This is in line with Yates and Barlow [44] who state that biopolymers often perform worse than conventional polymers in impact categories beyond global warming. The performance of wood for acidification, eutrophication and marine aquatic toxicity is sometimes better and sometimes worse compared to PP and PS. The abiotic depletion is always the lowest for wood.

\subsubsection{Sensitivity Analysis 1}

The sensitivity analysis showed that the LCIA results are most sensitive to a change of transportation distances in the case of abiotic depletion for wood and paper products (Table 2). 
This is explained by the overall lower abiotic depletion caused during the other life cycle phases of products made from renewable resources. Generally, it can be deducted from the sensitivity analysis that the overall results of this study are not very sensitive to a change in assumptions of the transportation scenario as the larger part of emissions is caused during over life cycle processes.

In the sensitivity analysis regarding the alternative EoL scenario, the biggest changes considering all impact categories can be observed for paper products. This can be explained by the high average paper recycling rate of $72.3 \%$ in the EU. However, this assumption is the best-case scenario which is unlikely to be achieved in reality. In fact, paper waste from single-use cotton buds, straws and plates is mixed with other materials and therefore often not recyclable.

The chosen correction factor (0.6) has a high impact on the alternative EoL scenario. For the paper industry, there is agreement that the correction factor should lie between 0.5 and $0.7[38,45]$. In the polymer industry there is less agreement but van der Harst et al. [38] chose a correction factor of 0.6 for PS based on 2015 market prices. Therefore, the correction factor chosen here seems justified but the authors are aware that it is an arbitrarily set value with significant impact on the results of this analysis which is discussed in more detail elsewhere (see [38]).

Of all impact categories, the EoL sensitivity analysis impacts GHG emissions the most. The reduction in GHG emissions from wood and PLA can be explained by the diverted amount of waste from landfill (25\%) which is composted instead. Under composting conditions, $\mathrm{CO}_{2}$ is released instead of $\mathrm{CH}_{4}$ during degradation which has a 28 times lower global warming potential according to the Intergovernmental Panel on Climate Change [46]. PS has a higher carbon footprint for the material production than for example $\mathrm{PP}$, due to its more complicated and energy-intensive production process (see Figure 1). Therefore, recovering material for secondary uses leads to a significant reduction of GHG emissions for PS (over 10\%).

Similar to the case of paper, the recycling rate (31.1\% for PP and PS) and composting rate (25\% for wood and PLA) describe an unlikely best-case scenario. Although cutlery and stirrers made of wood or PLA can be disposed of together with food waste, they are unlikely to end up in a composting facility [47]. Instead, they are more likely to be disposed of with the general waste fraction which is either landfilled or incinerated.

\subsubsection{The Single-Use Plastics Ban}

The results of the assessment of the single-use plastics ban are as expected, considering the product LCA results in Appendix A. It must be noted that the values produced by the assessment (Figure 2) are best estimates and heavily dependent on product weights as the error bars of the product LCAs (Figures A1-A8) indicate. Nevertheless, this analysis shows for wood and paper what has been shown before for biopolymers: "the results demonstrate real environmental trade-offs" [48].

The estimates of the EC and the estimates of this study concerning the reduction in GHG emissions and the reduction in release of plastic to the oceans are of the same order of magnitude. The EC [14] estimates the reduction in GHG emissions at 2.63 million tonnes per year while this study calculated GHG savings of 1.56 million tonnes of $\mathrm{CO}_{2} \mathrm{e}$ per year. The EC [14] predicts the reduction in plastic marine pollution from single-use plastics at 4850 tonnes per year while this study calculated a reduction in plastic marine pollution of 4960 tonnes per year. However, in the case of the EC estimates, it is unclear to what extent each of the measures of the single-use plastics directive reduces GHG emissions and plastic marine pollution. Furthermore, the present study has omitted the product category sticks for balloons due to a lack of data.

When considering the relative impacts of the plastics ban (Figure 3), the significant results are the increase in emissions contributing to marine aquatic toxicity and the decrease in plastic marine pollution. It should be mentioned that a normalisation with regional EU data is slightly flawed as there is no certainty as to whether the calculated emissions actually occur in the EU. 


\subsubsection{Sensitvity Analysis 2}

The results of the assessment of the single-use plastics ban are sensitive to a change in consumption figures. A reduction by $10 \%$ of the consumption of single-use items due to the introduction of the single-use plastics ban reduces the environmental impacts of all impact categories apart from plastic marine pollution. This is due to the fact that single-use non-plastic items do not cause plastic marine pollution. A 20\% reduction of consumption figures reduces the impacts even further. Such a reduction of consumption could occur due to an increased price of single-use non-plastic alternatives in comparison to single-use plastic items [11]. However, it is difficult to predict these consumption figures into the future with certainty.

\subsection{Discussion of Alternative Strategies to Tackle Plastic Marine Pollution}

Legislation and science can assist in deriving alternative strategies to address plastic marine pollution. The waste hierarchy gives clear guidance on how to address waste by defining a priority order in waste prevention and management legislation and policy: prevention, preparing for re-use, recycling, other recovery (e.g., energy recovery) and disposal [49]. The first strategy to tackle the problem of single-use plastic waste should therefore be the prevention of waste. Plastic bag levies have proven to be very effective in reducing consumption [6]. However, it remains open whether the observed reductions in consumption also led to a reduction in plastic use. For example, the thickness of the plastic could have increased [11].

In the context of plastic marine pollution, education and outreach programmes to modify behaviour were proposed [50]. The EC [14], however, argues that there is limited evidence on the effectiveness of awareness-raising campaigns. Although part of the single-use plastics directive, there is no clear guidance on how awareness-raising measures should be implemented in the member states. Studies show that littering habits differ, for example, between individuals in Western and Eastern European countries [51]. Although the availability of appropriate waste disposal structures certainly matters, this suggests that there is scope for raising more awareness, educating people and changing social norms regarding waste disposal.

A promising strategy for the EU to reduce worldwide plastic marine pollution is to stop exporting plastic waste to countries with high rates of inadequately managed waste such as China $(74 \%)$, Thailand $(73 \%)$, Vietnam (86\%), Indonesia (81\%), and Malaysia (55\%) [2]. Now that China itself has banned the import of nonindustrial plastic waste, the EU will most likely start exporting its plastic waste to other countries. Though the European Parliament [52] states that "member states shall ensure that exports of waste materials to third countries do not add to plastic marine litter elsewhere", the risk that plastic waste eventually leaks into oceans is not mentioned nor mitigated by the single-use plastics directive.

Finally, an improvement of the single-use plastics market restriction would be to mandate that products replacing single-use plastic items are certified to come from responsibly managed sources (e.g., Forest Stewardship Council certification).

\subsection{Discussion of the Sustainability of the Single-Use Plastics Ban}

For the discussion of the sustainability of the single-use plastics ban it is important to discuss the trade-off between marine aquatic toxicity and plastic marine pollution. It must be noted that the impact category of marine aquatic toxicity is not as well established as, for example, the impact categories of global warming and ozone layer depletion. Furthermore, for a substance to be toxic, the dose-response relationship is important; that is, if a substance is diluted it is less harmful to living organisms. However, a dose-response relationship for marine plastic is lacking too [53]. Consequently, no clear answer can be given as to whether 650 million tonnes of DCB equivalents or 4960 tonnes of marine plastic are worse for the environment.

The social and economic impacts of the single-use plastics ban were not considered in this study to narrow down its scope. Single-use non-plastic items are usually more expensive to produce than 
single-use plastic items [11]. However, the social and economic impacts are expected to be minimal as single-use items are often given away for free. When sustainability is understood literally, which means that a sustainable action can be sustained or maintained indefinitely, it becomes apparent that single-use items are intrinsically unsustainable: the average use time of a single-use plastic bag is twelve minutes [54] - the use time of other single-use items might be even shorter. It is the application of a material that can make it sustainable—no material is sustainable itself.

\section{Conclusions}

This study investigated whether banning plastic items is an appropriate strategy to protect the environment. Product LCAs were conducted for single-use plastic items and single-use non-plastic alternatives. The life cycle impacts of the two product categories were compared and scaled according to EU consumption. This study finds that single-use items cause emissions which are harmful to the environment regardless of their material composition. The common perception that products made from renewable resources are good for the environment is a partial truth and requires further qualification.

According to this analysis, it is unclear whether the plastics ban is beneficial to the environment since positive but also negative impacts on the environment are expected. The single-use plastics ban will decrease the EU's contribution to plastic marine pollution by $5.5 \%$ which equates to a $0.06 \%$ decrease globally [2]. It is concluded that the plastics ban will lead to only a small reduction of global plastic marine pollution and, thus, provides only a partial solution to the problem it intends to solve.

Alternatives to a single-use plastics ban exist, such as banning or imposing a premium price on single-use items regardless of their material composition, to reduce consumption and thereby pollution. Another promising strategy to reduce plastic marine pollution is to refrain from plastic waste exports into countries with high rates of mismanaged waste. An improvement of the single-use plastics ban would be a stronger emphasis on awareness raising to avoid inappropriate disposal in the EU and a requirement for paper and wood products to be certified to come from sustainable forestry sources.

\subsection{Implications}

The findings of this study have implications for policy and industry. As mentioned in the introduction, there is a current global trend towards single-use plastic policies. This study might contribute to the evidence base for future single-use plastic policies and support the improvement of already-existing policies. Furthermore, the findings stress that more effort is needed from policy makers to reduce the negative impacts of single-use items and to solve the problem of plastic marine pollution. Moreover, the single-use items industry might be interested in the findings. This study points to advantages and disadvantages in the life cycle of single-use plastic and single-use non-plastic products. The insights provided here could help the respective industries to mitigate existing problems and improve their environmental performance.

\subsection{Recommendations}

Based on the introduction (Section 1), the results (Section 3) and discussion (Section 4), recommendations were developed.

Recommendations to policy makers:

- The EU should stop exporting plastic waste (short-term).

- The EC should follow international standards such as ISO when performing assessments such as LCA (short-term).

- The EU should respect the waste hierarchy and increase its efforts to prevent waste. For that purpose, the EU should encourage its citizens to use fewer single-use items (e.g., by imposing a premium price on all single-use items) (long-term).

- The EU should focus on the mismanagement of waste and littering instead of banning certain plastic products. Banning is not promising as it would be difficult to ban all plastics (long-term). 
- The EU should only import certified paper and wood products if it intends to rely more strongly on the so-called bioeconomy (long-term).

Recommendations to industry:

- Wood and paper item retailers (e.g., vegware ${ }^{\mathrm{TM}}$ ) should reveal the LCI data of their products in the same way as NatureWorks ${ }^{\mathrm{TM}}$ has done (short-term).

\subsection{Limitations and Areas of Future Research}

This study could be followed up by a more extensive data collection. To refine the representativeness of the single-use items analysed in this study, a wider market study could be performed in order to reveal the share of products which exist on the market. The assumption that most single-use items are either incinerated or landfilled could be confirmed by a study which assesses the actual recycling and composting rates of single-use items made from different materials. The second assumption which requires confirmation is that the environmental impact of single-use paper products is equivalent to the environmental impact of paper more generally. A specific LCI study could be performed for small single-use paper products. Finally, actual market data on the consumption of single-use plates would have improved the reliability of this study.

Methodologically, a dynamic analysis and a location-specific analysis would improve this study. It would be worthwhile to perform a dynamic analysis of consumption patterns and changes in the background system (i.e., electricity supply) to give a more accurate outlook into the future. Such an outlook could also take into account the potential rise of biopolymers in the near future. Further research could investigate the actual location of emissions, considering the routes taken by single-use items in the global supply and waste chain. This would also help to refine the transportation distances assumed in this study.

This investigation suggests the use of other solutions to the problem of plastic marine pollution. Future research should explore whether the observed reduction in consumption of e.g., plastic bags after the introduction of a levy has led to a reduction of environmental impacts. Furthermore, research should reveal the environmental impacts of waste exports, particularly plastic waste exports. The effects of a plastic export ban in the EU should be investigated including an assessment of the environmental benefits and the feasibility of such an approach.

LCA combined with consumption data seems to be useful in the policy assessment context. It is worth investigating whether a similar approach could be applied to assess the environmental impacts of other industrial policies (i.e., in the transport sector). This could help to ensure that industrial policies are effective as well as beneficial to the environment.

Supplementary Materials: The following are available online at http://www.mdpi.com/2071-1050/12/9/3746/s1, Table S1: Product weights and results of the IR analysis, Table S2: Detailed process information, Figure S1: IR transmission spectrum of sample 1a, Figure S2: IR transmission spectrum of sample 2b, Figure S3: IR transmission spectrum of sample 2c, Figure S4: IR transmission spectrum of sample 3a, Figure S5: IR transmission spectrum of sample 3b, Figure S6: IR transmission spectrum of sample 3c, Figure S7: IR transmission spectrum of sample 3d, Figure S8: IR transmission spectrum of sample 4b, Figure S9: IR transmission spectrum of sample 5b, Figure S10: IR transmission spectrum of sample 6a, Figure S11: IR transmission spectrum of sample 6b, Figure S12: IR transmission spectrum of sample 6c, Figure S13: IR transmission spectrum of sample 6d, Figure S14: IR transmission spectrum of sample 7a, Figure S15: Photo of assessed cotton bud sticks, Figure S16: Photo of assessed cutlery, knives, Figure S17: Photo of assessed cutlery, forks, Figure S18: Photo of assessed cutlery, spoons, Figure S19: Photo of assessed cutlery, teaspoons, Figure S20: Photo of assessed straws, Figure S21: Photo of assessed stirrers, Figure S22: Photo of assessed plates.

Author Contributions: Conceptualization, T.H.; Formal analysis, T.H.; Investigation, T.H.; Methodology, T.H.; Software, T.H.; Supervision, C.Y.B. and M.F.; Visualization, T.H.; Writing-original draft, T.H.; Writing-review \& editing, C.Y.B. All authors have read and agreed to the published version of the manuscript.

Funding: This research received no external funding.

Conflicts of Interest: The authors declare no conflict of interest. 


\section{Appendix A. Life Cycle Impact Assessment Results}

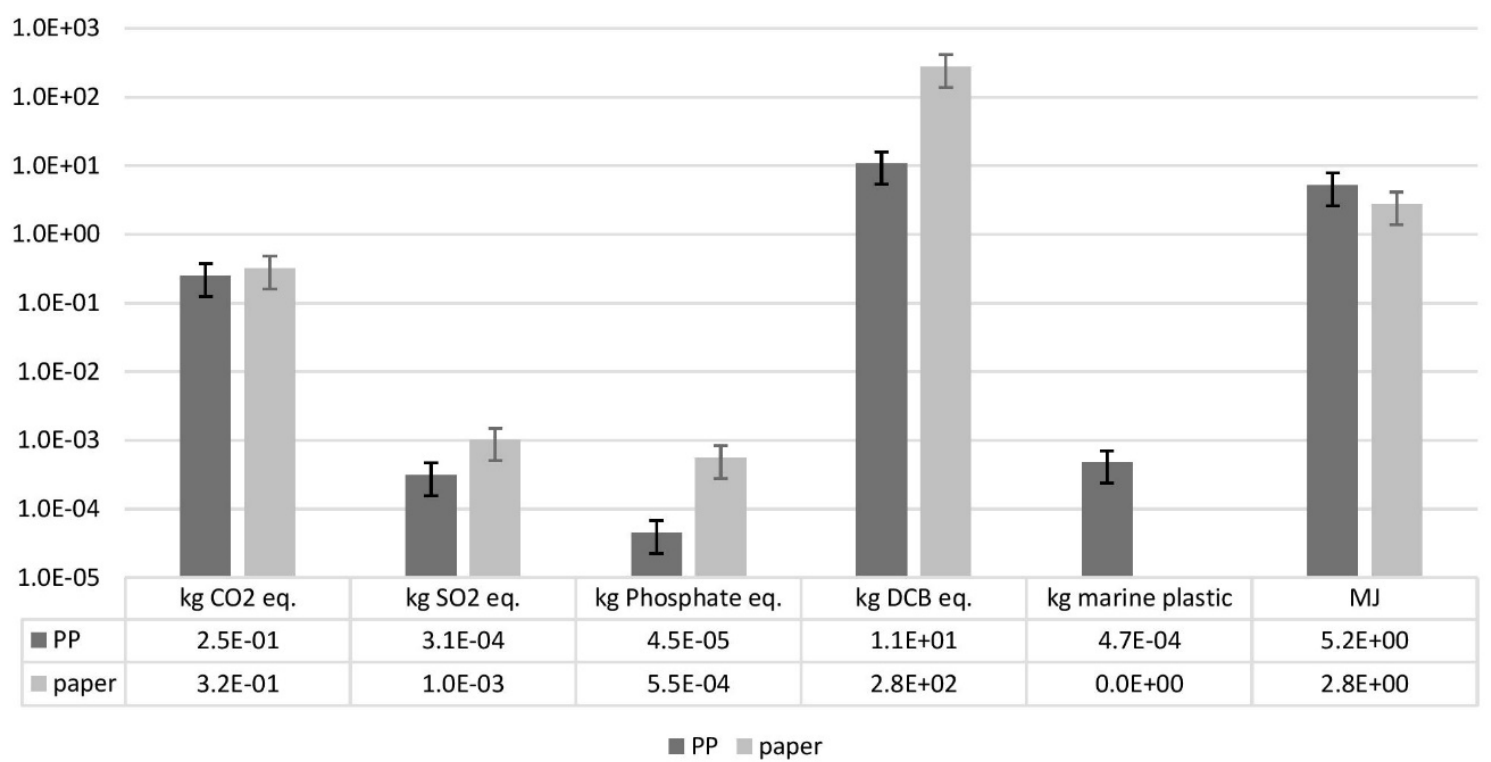

Figure A1. LCIA results for the six impact categories for single-use cotton bud sticks. The error bars show the LCIA results for a variation of product weights by $\pm 50 \%$.

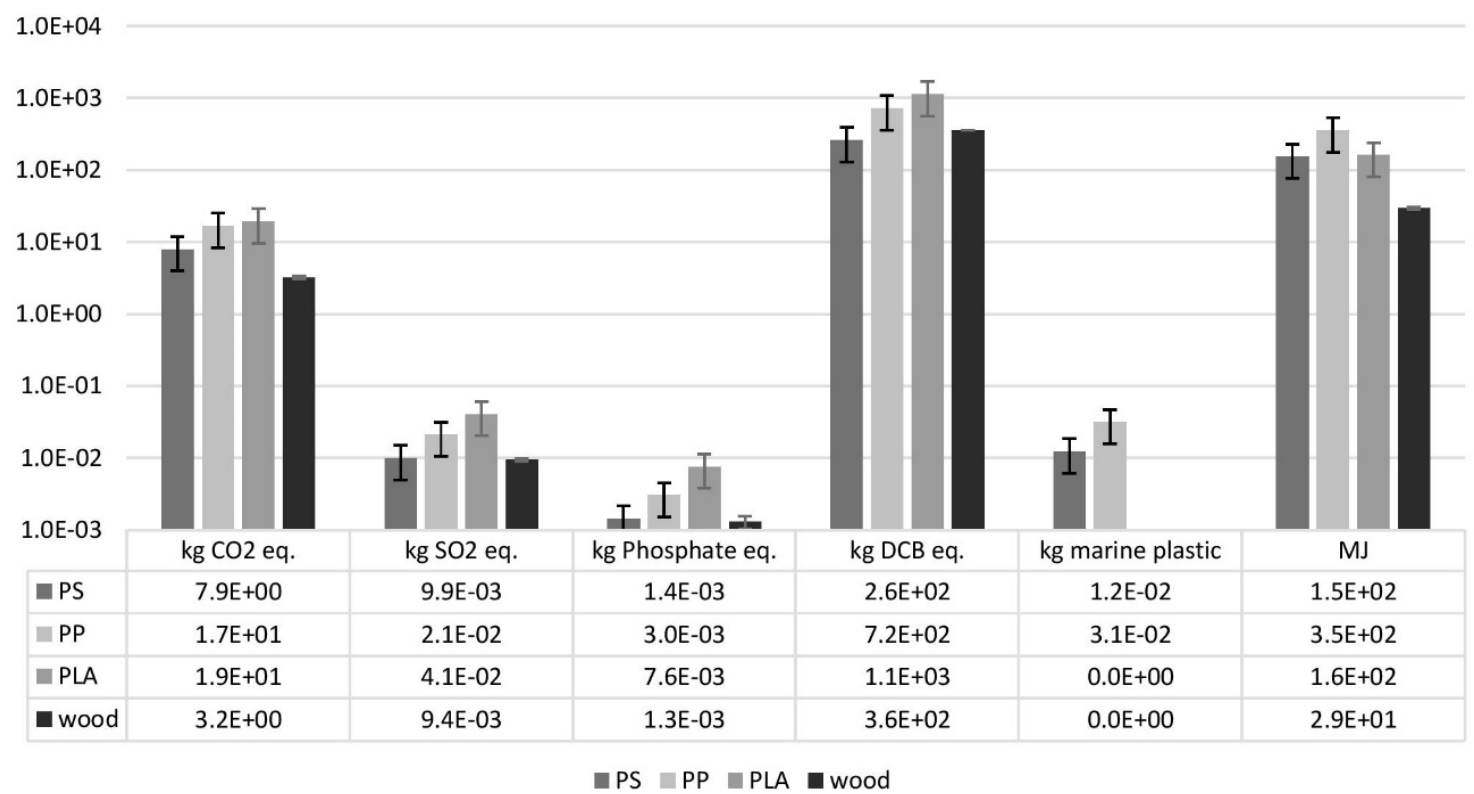

Figure A2. LCIA results for the six impact categories for single-use knives. The error bars show the LCIA results for a variation of product weights by $\pm 50 \%$. 


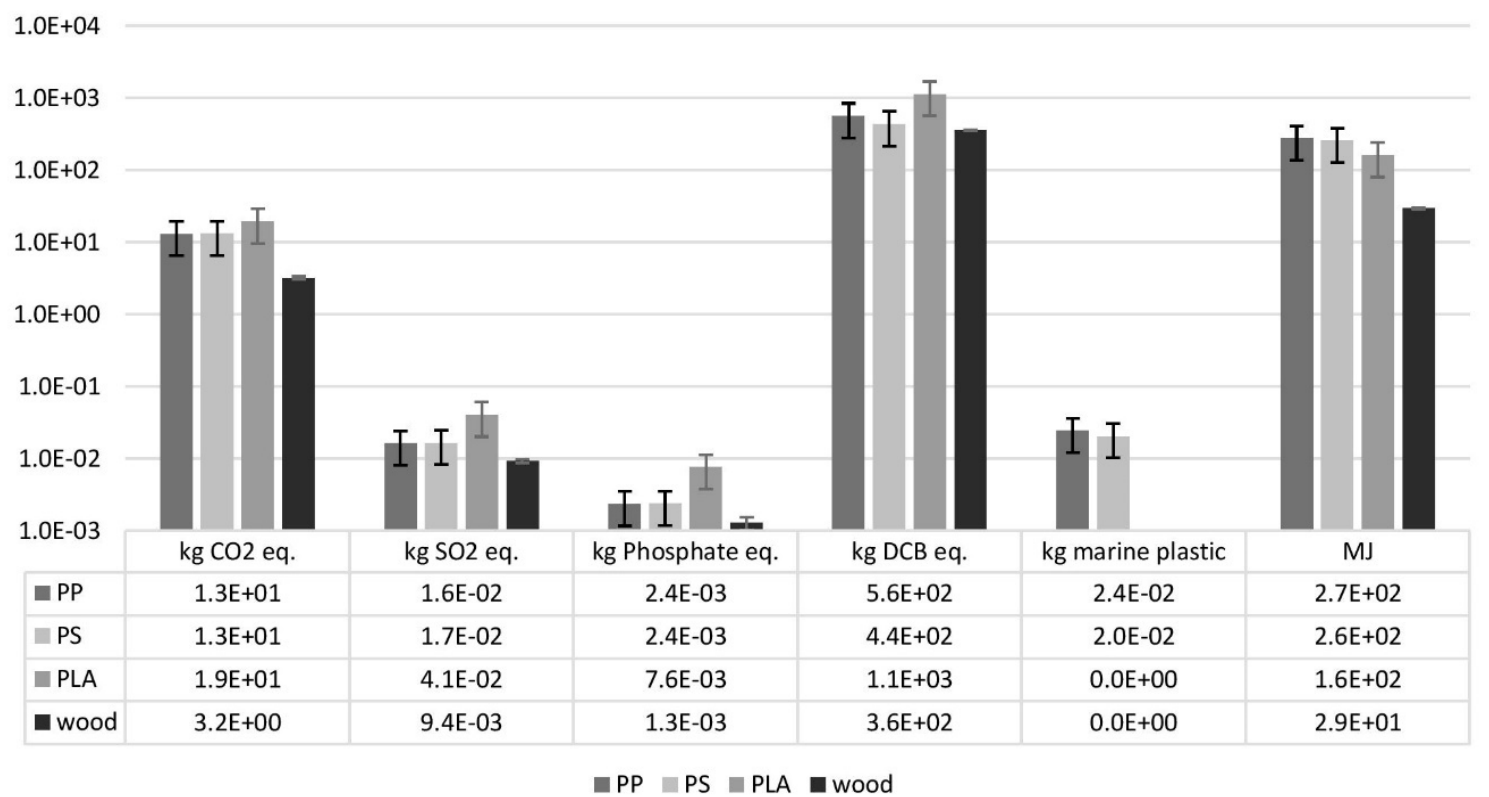

Figure A3. LCIA results for the six impact categories for single-use forks. The error bars show the LCIA results for a variation of product weights by $\pm 50 \%$.

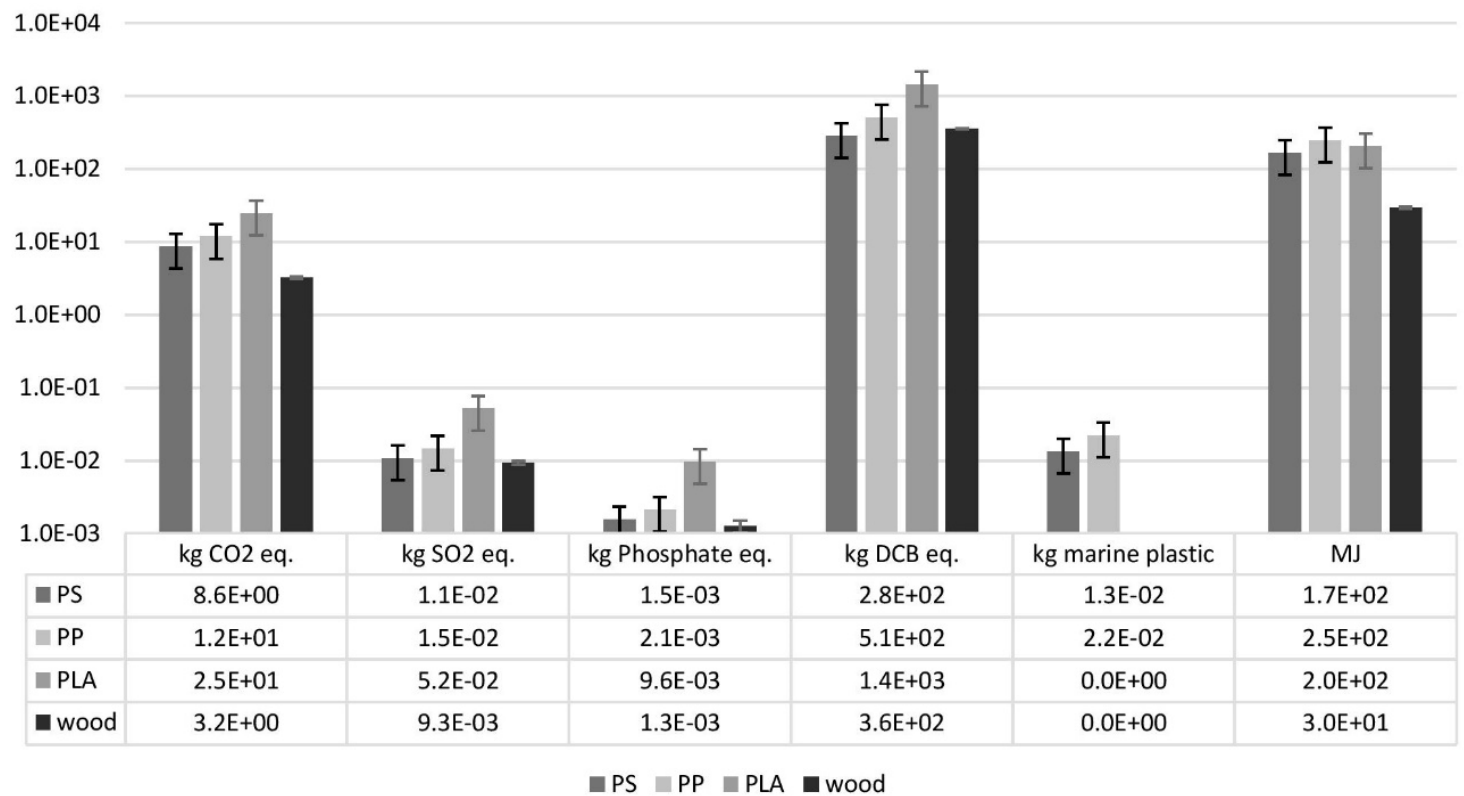

Figure A4. LCIA results for the six impact categories for single-use spoons. The error bars show the LCIA results for a variation of product weights by $\pm 50 \%$. 


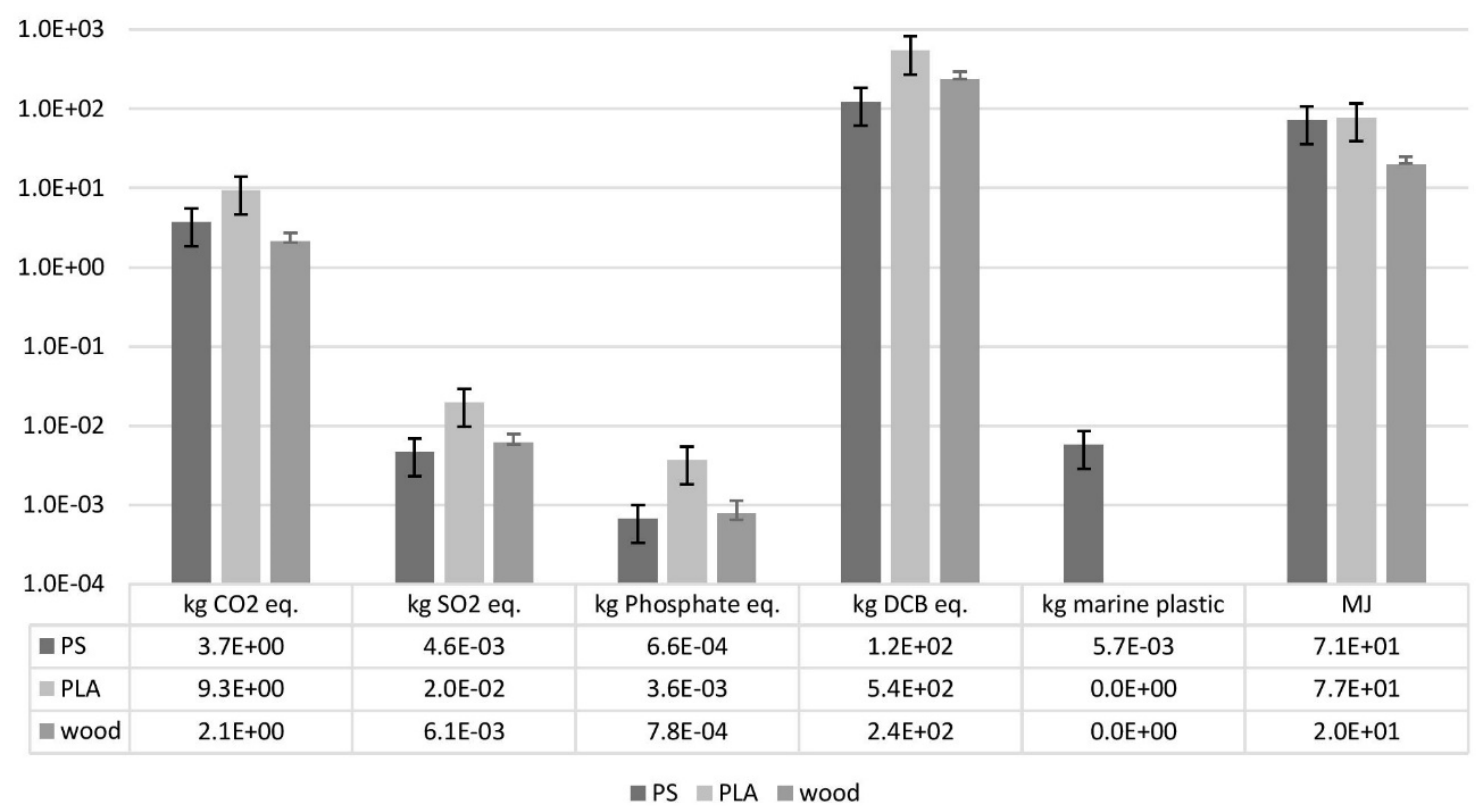

Figure A5. LCIA results for the six impact categories for single-use teaspoons. The error bars show the LCIA results for a variation of product weights by $\pm 50 \%$.

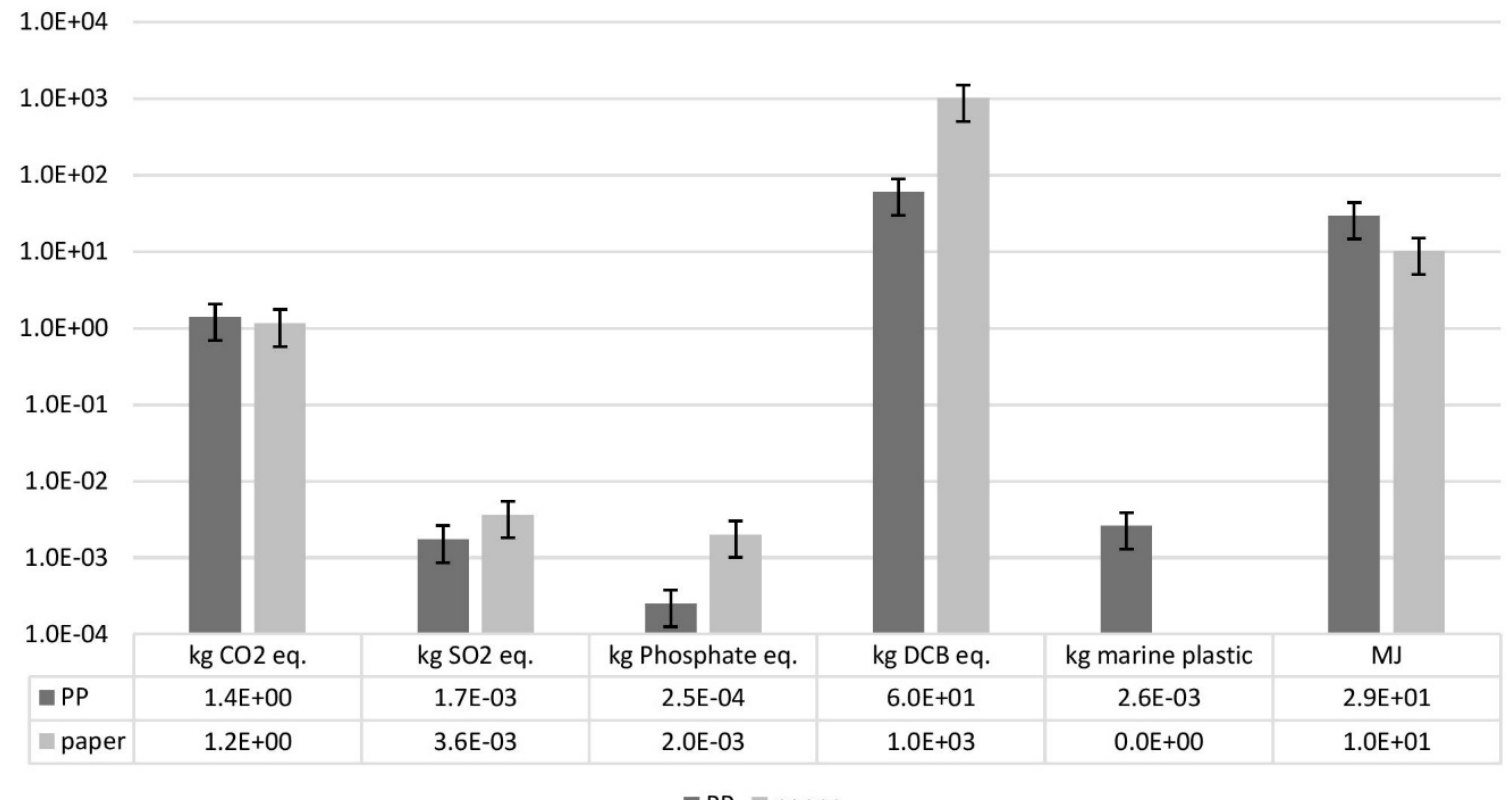

- PP

Figure A6. LCIA results for the six impact categories for single-use straws. The error bars show the LCIA results for a variation of product weights by $\pm 50 \%$. 


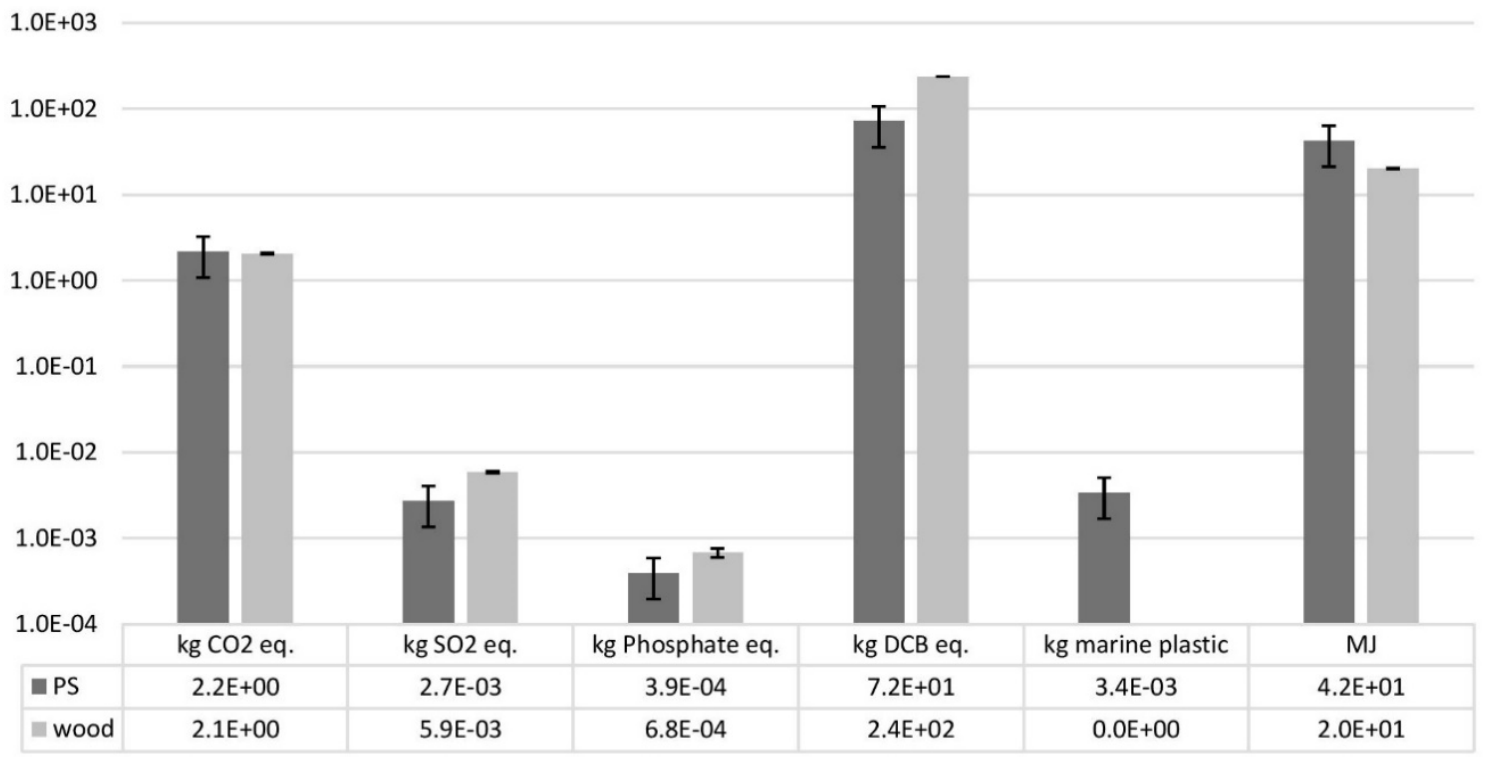

- $\mathrm{PS} \backsim \operatorname{wood}$

Figure A7. LCIA results for the six impact categories for single-use stirrers. The error bars show the LCIA results for a variation of product weights by $\pm 50 \%$.

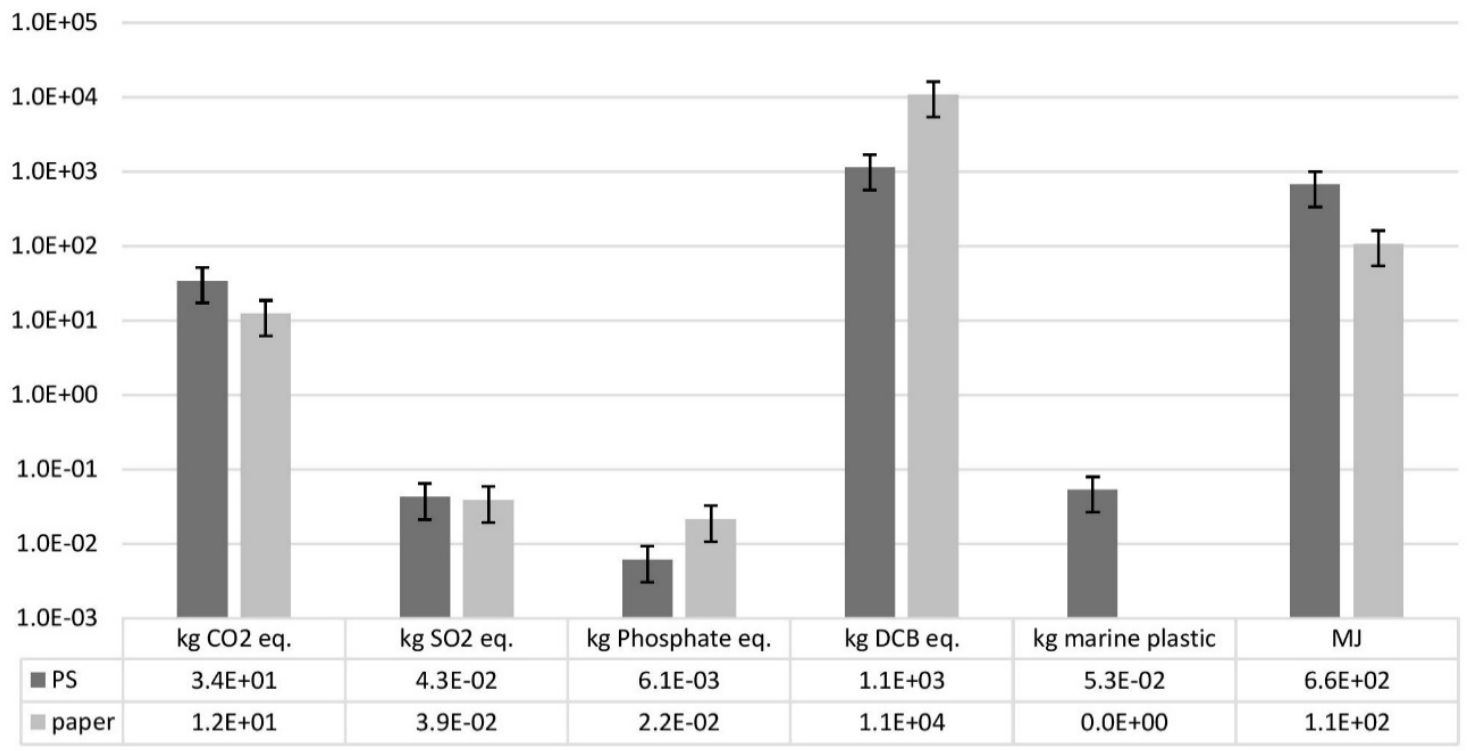

口S - paper

Figure A8. LCIA results for the six impact categories for single-use plates. The error bars show the LCIA results for a variation of product weights by $\pm 50 \%$.

\section{References}

1. PlasticsEurope. Plastics—The Facts 2018: An Analysis of European Plastics Production, Demand and Waste Data; PlasticsEurope: Brussels, Belgium, 2018.

2. Jambeck, J.R.; Geyer, R.; Wilcox, C.; Siegler, T.R.; Perryman, M.; Andrady, A.; Narayan, R.; Law, K.L. Plastic waste inputs from land into the ocean. Science 2015, 347, 768-771. [CrossRef] [PubMed]

3. Geyer, R.; Jambeck, J.R.; Law, K.L. Production, use, and fate of all plastics ever made. Sci. Adv. 2017, 3, e1700782. [CrossRef] [PubMed]

4. Barnes, D.K.A.; Galgani, F.; Thompson, R.C.; Barlaz, M. Accumulation and fragmentation of plastic debris in global environments. Philos. Trans. R. Soc. B Biol. Sci. 2009, 364, 1985-1998. [CrossRef] [PubMed] 
5. Thompson, R.C.; Moore, C.J.; vom Saal, F.S.; Swan, S.H. Plastics, the environment and human health: Current consensus and future trends. Philos. Trans. R. Soc. B Biol. Sci. 2009, 364, 2153-2166. [CrossRef]

6. Xanthos, D.; Walker, T.R. International policies to reduce plastic marine pollution from single-use plastics (plastic bags and microbeads): A review. Mar. Pollut. Bull. 2017, 17-26. [CrossRef]

7. Gall, S.C.; Thompson, R.C. The impact of debris on marine life. Mar. Pollut. Bull. 2015, 92, 170-179. [CrossRef]

8. Seltenrich, N. New Link in the Food Chain? Marine Plastic Pollution and Seafood Safety. Environ. Health Perspect. 2015, 123, A34-A41. [CrossRef]

9. UNEP. Legal Limits on Single-Use Plastics and Microplastics: A Global Review of National Laws and Regulations; UNEP: Nairobi, Kenya, 2018.

10. Rochman, C.M.; Browne, M.A.; Halpern, B.S.; Hentschel, B.T.; Hoh, E.; Karapanagioti, H.K.; Rios-Mendoza, L.M.; Takada, H.; Teh, S.; Thompson, R.C. Classify plastic waste as hazardous. Nature 2013, 494, 169-171. [CrossRef]

11. Wagner, T.P. Reducing single-use plastic shopping bags in the USA. Waste Manag. 2017, 70, 3-12. [CrossRef]

12. Secretariat of the Convention on Biological Diversity and the Scientific and Technical Advisory Panel—Global Environment Facility. Impacts of Marine Debris on Biodiversity: Current Status and Potential Solutions; CBD Technical Series; Secretariat of the Convention on Biological Diversity: Montreal, QC, Canada, 2012; Volume 67, pp. 11-26.

13. European Commission, Directorate-General for Environment. Proposal for a Directive of the European Parliament and of the Council on the Reduction of the Impact of Certain Plastic Products on the Environment; DG ENV: Brussels, Belgium, 2018.

14. European Commission, Directorate-General for Environment. Impact Assessment_Reducing Marine Litter: Action on Single Use Plastics and Fishing Gear; DG ENV: Brussels, Belgium, 2018.

15. European Commission, Directorate-General for Environment. Life Cycle Inventories of Single Use Plastic Products and their Alternatives; DG ENV: Brussels, Belgium, 2018.

16. European Parliamentary Research Service. Towards a Circular Economy-Waste Management in the EU; Scientific Foresight Unit: Brussels, Belgium, 2017; ISBN 978-92-846-1548-3.

17. EC. Assessment of Measures to Reduce Marine Litter from Single Use Plastics; Publications Office of the European Union: Luxembourg, 2018; ISBN 978-92-79-92898-7.

18. Petersen, A.K.; Solberg, B. Environmental and economic impacts of substitution between wood products and alternative materials: A review of micro-level analyses from Norway and Sweden. For. Policy Econ. 2005, 7, 249-259. [CrossRef]

19. Petersen, A.K.; Solberg, B. Greenhouse Gas Emissions and Costs over the Life Cycle of Wood and Alternative Flooring Materials. Clim. Chang. 2004, 64, 143-167. [CrossRef]

20. Werner, F.; Richter, K. Wooden building products in comparative LCA: A literature review. Int. J. Life Cycle Assess. 2007, 12, 470-479. [CrossRef]

21. Lewis, H.; Verghese, K.; Fitzpatrick, L. Evaluating the sustainability impacts of packaging: The plastic carry bag dilemma. Packag. Technol. Sci. 2010, 23, 145-160. [CrossRef]

22. Mattila, T.; Kujanpää, M.; Dahlbo, H.; Soukka, R.; Myllymaa, T. Uncertainty and Sensitivity in the Carbon Footprint of Shopping Bags. J. Ind. Ecol. 2011, 15, 217-227. [CrossRef]

23. Edwards, C.; Fry, J.M. Life Cycle Assessment of Supermarket Carrier Bags: A Review of the Bags Available in 2006; Environment Agency: Bristol, UK, 2011.

24. Boucher, J.; Billard, G. The challenges of measuring plastic pollution. Field Actions Sci. Rep. 2019, 19, 68-75.

25. Schweitzer, J.-P.; Petsinaris, F.; Gionfra, C. A study by Zero Waste Europe and Friends of the Earth Europe for the Rethink Plastic Alliance. Justifying Plastic Pollution: How Life Cycle Assessments are Misused in Food Packaging Policy; Institute for European Environmental Policy (IEEP): Brussels, Belgium, 2018.

26. Woods, J.S.; Veltman, K.; Huijbregts, M.A.J.; Verones, F.; Hertwich, E.G. Towards a meaningful assessment of marine ecological impacts in life cycle assessment (LCA). Environ. Int. 2016, 89, 48-61. [CrossRef]

27. Woods, J.S.; Rødder, G.; Verones, F. An effect factor approach for quantifying the entanglement impact on marine species of macroplastic debris within life cycle impact assessment. Ecol. Indic. 2019, 99, 61-66. [CrossRef]

28. Civancik-Uslu, D.; Puig, R.; Hauschild, M.; Fullana-i-Palmer, P. Life cycle assessment of carrier bags and development of a littering indicator. Sci. Total Environ. 2019, 685, 621-630. [CrossRef] 
29. ISO. ISO 14040: Environmental Management_Life Cycle Assessment_Principles and Framework; International Organization for Standardization: Genève, Switzerland, 2006; ISBN 978-0-580-48992-1.

30. ISO. ISO 14044: Environmental Management_Life Cycle Assessment_Requirements and Guidelines; International Organization for Standardization: Genève, Switzerland, 2006; ISBN 978-0-580-48992-1.

31. CML. CML-IA-CML Characterization Factors Version 3.4; Centrum voor Milieuwetenschappen Leiden (Institute of Environmental Science): Leiden, The Netherlands, 2008.

32. Guinée, J.; Gorrée, M.; Heijungs, R.; Huppes, G.; Kleijn, R.; de Koning, A.; van Oers, L.; Wegener Sleeswijk, A.; Suh, S.; Udo de Haes, H.; et al. LCA-An Operational Guide to the ISO-Standards_Part 2a; Leiden University: Leiden, The Netherlands, 2001.

33. Abdel-Rahman, M.A.; Tashiro, Y.; Sonomoto, K. Recent advances in lactic acid production by microbial fermentation processes. Biotechnol. Adv. 2013, 31, 877-902. [CrossRef]

34. Okeaya International Co., Ltd. Wooden Fork Machine, Wooden Spoon Machine, Wooden Knife Machine-Okeaya International Co., Ltd. Available online: http://www.okeaya.com/product-cat-14.html (accessed on 15 May 2019).

35. Shenyang Romiter Machinery Co. Ltd. Wood Cutlery Production Line. Available online: https://www. woodstickmachine.com/products/disposable-wood-cutlery-making-machine/ (accessed on 15 May 2019).

36. Pöyry Forest Industry Consulting Ltd.; Oxford Economics Ltd. Wood Waste Market in the UK; WRAP: Banbury, UK, 2009.

37. Papong, S.; Malakul, P.; Trungkavashirakun, R.; Wenunun, P.; Chom-in, T.; Nithitanakul, M.; Sarobol, E. Comparative assessment of the environmental profile of PLA and PET drinking water bottles from a life cycle perspective. J. Clean. Prod. 2014, 65, 539-550. [CrossRef]

38. van der Harst, E.; Potting, J.; Kroeze, C. Comparison of different methods to include recycling in LCAs of aluminium cans and disposable polystyrene cups. Waste Manag. 2016, 48, 565-583. [CrossRef] [PubMed]

39. European Paper Recycling Council (EPRC). Monitoring Report 2017 European Declaration on Paper Recycling 2016-2020; European Paper Recycling Council: Brussels, Belgium, 2017.

40. European Compost Network Bio-Waste in Europe. Available online: https:/www.compostnetwork.info/ policy/biowaste-in-europe/ (accessed on 11 June 2019).

41. Arena, U.; Mastellone, M.L.; Perugini, F.; Clift, R. Environmental Assessment of Paper Waste Management Options by Means of LCA Methodology. Ind. Eng. Chem. Res. 2004, 43, 5702-5714. [CrossRef]

42. Transparency Market Research. Food Service Packaging Market: Global Industry Analysis and Forecast 2017-2020. Available online: https://www.transparencymarketresearch.com/food-service-packaging-market. html (accessed on 17 August 2017).

43. Global Data Cotton Buds Market: Growth, Opportunities, Share and Competitive Analysis, 2018-2026; 2018. Available online: https://www.prnewswire.com/news-releases/cotton-buds-world-industry-report-20182026-analysis-by-material-application-and-geography-300675866.html (accessed on 3 July 2018).

44. Yates, M.R.; Barlow, C.Y. Life cycle assessments of biodegradable, commercial biopolymers-A critical review. Resour. Conserv. Recycl. 2013, 78, 54-66. [CrossRef]

45. Cederstrand, P.; Riise, E.; Uihlein, A. Evaluation of recycling and allocation methods for paper. Swed. Life Cycle Cent. Rapp. 2014, 1, 36.

46. Myhre, G.; Shindell, D.; Bréon, F.-M.; Collins, W.; Fuglestvedt, J.; Huang, J.; Koch, D.; Lamarque, J.-F.; Lee, D.; Mendoza, B.; et al. Anthropogenic and Natural Radiative Forcing. In Climate Change 2013: The Physical Science Basis. Contribution of Working Group I to the Fifth Assessment Report of the Intergovernmental Panel on Climate Change; Cambridge University Press: Cambridge, UK; New York, NY, USA, 2013; p. 82.

47. Schneiderman, D.K.; Hillmyer, M.A. 50th Anniversary Perspective: There Is a Great Future in Sustainable Polymers. Macromolecules 2017, 50, 3733-3749. [CrossRef]

48. Hottle, T.A.; Bilec, M.M.; Landis, A.E. Biopolymer production and end of life comparisons using life cycle assessment. Resour. Conserv. Recycl. 2017, 122, 295-306. [CrossRef]

49. European Parliament. Directive 2008/104/EC of the European Parliament and of the Council of 19 November 2008 on Waste and Repealing Certain Directives; European Parliament: Brussels, Belgium, 2008; pp. 426-429. Available online: https://eur-lex.europa.eu/legal-content/EN/TXT/?qid=1588400368488\&uri= CELEX:32008L0104 (accessed on 19 November 2008).

50. Kershaw, P.; Katsuhiko, S.; Lee, S.; Samseth, J.; Woodring, D. Plastic debris in the ocean. In UNEP Year Book; United Nations Environment Programme: Nairobi, Kenya, 2011; pp. 20-33. 
51. Torgler, B.; Frey, B.S.; Wilson, C. Environmental and Pro-Social Norms: Evidence on Littering. BE J. Econ. Anal. Policy 2009, 9. [CrossRef]

52. Reduction of the Impact of Certain Plastic Products on the Environment ${ }^{* *} \mathrm{I}$. European Parliament Legislative Resolution of 27 March 2019 on the Proposal for a Directive of the European Parliament and of the Council on the Reduction of the Impact of Certain Plastic Products on the Environment (COM(2018)0340-C8-0218/2018-2018/0172(COD)). Available online: https://www.europarl.europa.eu/doceo/ document/TA-8-2019-0305_EN.html (accessed on 27 March 2019).

53. François, G.; Georg, H.; Stefanie, W.; de, L.; Piha, H.; Valeria, A.; Alcaro, L.; Constança, B.; Brooks, C.; Brooks, C.; et al. Marine Strategy Framework Directive-Good Environmental Status-Technical Subgroup on Marine Litter Marine Litter Technical Recommendations for the Implementation of MSFD Requirements. ICES J. Mar. Sci. 2013, 7, 1055-1064.

54. New South Wales and Environment Protection Authority. Environment Protection. Authority Plastic Shopping Bags Options Paper: Practical Actions for Plastic Shopping Bags; Environment Protection Authority: Sydney, Australia, 2016; ISBN 978-1-76039-299-4.

(C) 2020 by the authors. Licensee MDPI, Basel, Switzerland. This article is an open access article distributed under the terms and conditions of the Creative Commons Attribution (CC BY) license (http://creativecommons.org/licenses/by/4.0/). 